\title{
Efeito do Treinamento Físico no Pulmão de Ratos Submetidos à Ingestão Alcoólica
}

\author{
Effects of Physical Training on Lungs of Rats \\ Submitted to Alcohol Intake
}

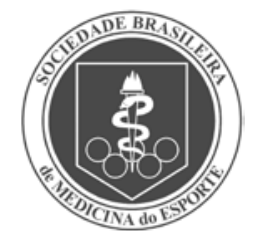

Artigo Original
André Machado Xavier ${ }^{1}$ Karla Fabiana Goessler ${ }^{1}$ Osny Ferrari Luiz Carlos Juliani' Fábio Goulart de Andrade Solange de Paula Ramos ${ }^{1}$

1. Departamento de Histologia - Centro de Ciências Biológicas Universidade Estadual de Londrina Londrina, PR.

\footnotetext{
Endereço para correspondência:

Solange de Paula Ramos

Departamento de Histologia Universidade Estadual de Londrina, Rodovia Celso Garcia Cid PR 445, km 380, Campus Universitário - 86055-900 - Londrina, PR.

E-mail: ramossolange@yahoo.com
}

\begin{abstract}
RESUMO
O alcoolismo crônico provoca alterações nos tecidos pulmonares caracterizadas por edema pulmonar e formação de extenso infiltrado inflamatório. O objetivo deste trabalho foi avaliar o efeito do exercício físico sobre as lesões pulmonares provocadas por ingestão crônica de álcool em ratos Wistar. Material e métodos: Trinta e dois ratos Wistar machos (261,1 \pm 1,3 gramas) receberam aguardente de cana-de-açúcar diluída (30\%, v/v, grupo alcoolizado) ou água potável (grupo controle) durante 120 dias. Após este período, cinco animais de cada grupo foram sacrificados. Os demais animais receberam apenas água potável até o final do experimento e foram divididos em quatro grupos: alcoolizados sedentários (AS), controle sedentários (CS), alcoolizados treinados (AT) e controles treinados (CT). Os animais AT e CT foram submetidos a protocolo de natação, aumentando gradativamente o tempo de exercício até 20 minutos por dia, cinco vezes por semana, durante um período total de cinco semanas. Neste mesmo período, os animais AS e CS foram mantidos em sedentarismo. Resultados: Após o período de ingestão alcoólica, os animais do grupo alcoolizado apresentaram redução de peso $(P<0,05)$ e aumento da massa relativa do pulmão $(P<0,05)$. O pulmão do grupo alcoolizado apresentou edema pulmonar e extenso infiltrado inflamatório. Os animais dos grupos CS e CT não apresentaram diferenças morfológicas. Os animais do grupo AT apresentaram aumento do quadro de edema pulmonar e do número de macrófagos pigmentados em relação ao grupo $A C(P<0,05)$. Conclusão: O exercício físico pode acentuar o processo inflamatório pulmonar quando aplicado em animais com lesão pulmonar inflamatória provocada pelo consumo crônico de álcool.
\end{abstract}

Palavras-chave: etanol, edema pulmonar, exercício.

\begin{abstract}
Chronic alcohol consumption causes alterations in the lung tissues characterized by edema and formation of large inflammatory infiltrate. The purpose of this work was to evaluate the effect of physical exercise on lung injuries caused by chronic alcohol intake in Wistar rats. Material and methods:Thirty-two male Wistar rats $(261.1 \pm 1.3 \mathrm{~g})$ received sugarcane distilled alcoholic beverage diluted (30\%, v/v, alcohol group) or tap water (control group) for 120 days. After this period, five animals of each group were sacrificed. The remaining animals received water and were sorted in four groups: alcoholic and sedentary (AS), control and sedentary (CS), alcoholic and trained (AT) and control and trained (CT). The AT and CT groups were submitted to a swimming exercise protocol with progressive daily increase in the training time until 20 minutes per day, five times per week, for five weeks. For the same period, AS and CS groups were maintained at sedentary state. Results: after the alcoholic intake period, the alcohol group presented decreased $(P<0.05)$ body weight and increased relative lung weight $(P<0.05)$. Lungs of alcoholic group showed characteristics of edema and inflammatory infiltrate. The CS and CT groups did not present morphological changes. AT animals showed increased inflammation and number of hyper pigmented macrophages in relation to CT group. Conclusion: exercise can increase lung inflammation when applied in animals with inflammatory injury induced by chronic alcohol consumption.
\end{abstract}

Keywords: alcohol, lung edema and exercise.

\section{INTRODUÇÃO}

A associação do alcoolismo e lesão pulmonar é um importante problema de saúde pública, por apresentar alta taxa de mortalidade e piorar a qualidade de vida dos indivíduos que sofreram lesões pulmonares agudas ou crônicas ${ }^{(1-4)}$. O consumo crônico de álcool está associado ao desenvolvimento de insuficiência respiratória, edema pulmonar e aumento da susceptibilidade às infecções respiratórias ${ }^{(1,5)}$. As alterações pulmonares podem ser causadas por ação direta do etanol sobre as funções dos pneumócitos tipo I e ll, alteração da permeabilidade epitelial, diminuição da produção da camada surfactante e remoção de líquidos, redução das defesas antioxidantes e resposta inflamatória local, exacerbada ${ }^{(1,5-8)}$. As alterações morfofuncionais também podem 
estar associadas à hipertensão arterial, causada pelo aumento da conversão da angiotensina II ou secundária à pancreatite alcoólica(8). Os mecanismos etiopatogênicos da pneumopatia alcoólica e o desenvolvimento de estratégias terapêuticas podem ser avaliados por meio de estudos experimentais em ratos. Em modelos experimentais, o efeito deletério do estresse oxidativo provocado pelo etanol, além da ação direta da droga e produtos do seu metabolismo sobre o tecido pulmonar, são os principais mecanismos indutores de inflamação, edema e fibrose intersticial ${ }^{(5,7)}$.

O exercício físico moderado e crônico tem sido associado a diversos efeitos benéficos à saúde, incluindo o aumento das defesas antioxidantes celulares e o controle da hipertensão arterial ${ }^{(9-11)}$. Em ratos, o treinamento físico demonstrou proteção contra os efeitos lesivos do álcool no sistema cardiovascular e nos músculos estriados esqueléticos ${ }^{(11,12)}$. Os efeitos protetores do exercício físico sobre lesões de isquemia e reperfusão, particularmente o aumento da atividade de sistemas antioxidantes, foram demonstrados em pulmão de ratos sedentários e treinados ${ }^{(13)}$. Embora seja demonstrada experimentalmente a proteção induzida pelo exercício físico moderado em animais submetidos concomitantemente à dieta alcoólica ${ }^{(12-14)}$, os efeitos do exercício físico sobre a reparação de lesões alcoólicas já instaladas foram pouco investigados, particularmente sobre o aparelho respiratório. 0 objetivo deste trabalho foi investigar o efeito do exercício físico de baixa intensidade na reparação de lesões dos tecidos pulmonares provocadas por ingestão crônica de álcool em ratos.

\section{MATERIAL E MÉTODOS}

\section{Animais e protocolo experimental}

Trinta e dois ratos Wistar machos, pesando 261,1 \pm 1,3 gramas, foram mantidos em gaiolas individuais, no Biotério de Experimentação Animal do Departamento de Histologia da Universidade Estadual de Londrina, a aproximadamente $24^{\circ} \mathrm{C}$, com ciclo claro/escuro de 12 horas. Os animais foram alimentados ad libitum com ração em pellet CR1 $\left(\right.$ Nuvilab $\left.^{\circledR}\right)$.

Os animais foram divididos em dois grupos de 16 animais: um grupo foi submetido à dieta líquida de álcool etílico (aguardente de cana-de-açúcar) e o outro grupo de animais recebeu água potável (controle). Aos 120 dias, cinco animais do grupo controle e cinco animais do grupo álcool foram sacrificados. Após este período, os demais animais passaram a receber apenas água potável e foram divididos em quatro grupos:

- CS: controle sedentário $(n=5)$

- CT: controle treinado $(n=6)$

- AS: alcoolizado sedentário $(n=5)$

- AT: alcoolizado treinado $(n=6)$

Os procedimentos experimentais foram realizados em conformidade com o Comitê de Ética em Experimentação Animal da Universidade Estadual de Londrina, parecer no 16/07, processo no 12.242/07.

\section{Protocolo de ingestão alcoólica}

Os animais submetidos à ingestão alcoólica foram tratados conforme o modelo de alcoolismo semivoluntário(15). A única fonte de líquidos disponíveis para os animais submetidos à dieta alcoólica foi aguardente destilada de cana-de-açúcar nas seguintes diluições e tempos: 10\%, durante 10 dias; 15\%, durante 11 dias; 20\%, durante 12 dias; $25 \%$, durante 12 dias; e 30\% a partir do 45 dia até o 120 dia. Após este período, os animais receberam água potável sem adição de aguardente. Durante todo o período experimental, o consumo de água e álcool foi medido diariamente.

\section{Protocolo de treinamento físico}

Os animais foram submetidos a protocolo de treinamento físico de natação, em tanques individuais $(37 \times 30 \mathrm{~cm}$, com $31 \mathrm{~cm}$ de água aquecida a $32 \pm 2^{\circ} \mathrm{C}$ ). No primeiro dia, os animais foram mantidos durante cinco minutos nos tanques para seleção dos animais com comportamento de natação espontâneo. Os animais foram submetidos à natação, sem carga, cinco dias por semana, iniciando com cinco minutos de treino e aumentando progressivamente cinco minutos, semanalmente, até o tempo total de 20 minutos/dia de treino. $O$ treino teve duração total de oito semanas.

\section{Análise histopatológica}

Um dia após o término do treinamento, cinco animais do grupo controle e do grupo alcoolizado foram sedados em éter etílico e sacrificados por deslocamento cervical. O animal e os pulmões foram pesados em balança analítica (Micronal ${ }^{\circledR} ; 0,001 \mathrm{~g}$ ). Em seguida, os pulmões foram lavados em solução salina e fixados em solução de Bouin alcoólico durante 24 horas. Após a inclusão em parafina histológica, secções de $7 \mu \mathrm{m}$ foram coradas com hematoxilina e eosina e analisados em microscópio de luz. Foram analisados 10 campos aleatórios por lâmina e as imagens foram registradas em sistema de captura de imagens (Motican, Motic, Hong Kong, China) e analisadas em software Image Plus 2.0 (Motic, Hong Kong, China). As áreas de edema foram calculadas pela razão entre a área ocupada pelos septos interalveolares e a área total do campo analisado. O número de macrófagos pigmentados foi determinado em imagens capturadas no aumento de 400 vezes.

\section{Análise estatística}

A distribuição de normalidade dos dados foi avaliada por meio de teste de Shapiro Wilk e foram aplicados testes não paramétricos quando não observada distribuição normal $(P<0,05)$. Foram utilizados teste $t$ de Student (dados paramétricos) ou U de Mann-Whitney (dados não-paramétricos), para comparação entre os animais sacrificados aos 120 dias. Comparações entre os grupos sacrificados após o período de treinamento foram realizadas com testes ANOVA e post hoc de Tukey (dados paramétricos) ou testes de Kruscal-Wallis e post hoc de Dunn (dados não-paramétricos). As diferenças foram consideradas significantes quando o teste bicaudal apresentou $P<0,05$. Os dados foram processados no programa estatístico SPSS (Statistical Package for the Social Sciences) versão 18,0.

\section{RESULTADOS}

O peso dos animais sacrificados imediatamente após o término do período de ingestão alcoólica (120 dias) e após o período de treinamento (176 dias) está demonstrado na figura 1. Os animais alcoolizados apresentaram redução de peso em relação aos animais controle. Após o período de treinamento, os animais CS, CT, AS e AT não apresentaram diferença significativa de peso. Os animais dos grupos controle e alcoolizados sacrificados aos 120 dias apresentaram consumo de líquido semelhante $(P>0,05$, teste $U$ de Mann-Whitney) na última semana antes do sacrifício (48,9 \pm 9,6ml/dia e 65,6 \pm 18,2 $\mathrm{ml} /$ dia, respectivamente). Quanto ao consumo de água, não foram encontradas diferenças durante a última semana antes do sacrifício entre os grupos CS $(66,7 \pm 27,8 \mathrm{ml} / \mathrm{dia})$, CT $(63 \pm 24,6 \mathrm{ml} / \mathrm{dia})$ e AS $(65,4 \pm 12,7 \mathrm{ml} / \mathrm{dia})$. O grupo AT apresentou redução da ingesta líquida $(45,2 \pm 4,8 \mathrm{ml} / \mathrm{dia})$, em relação ao grupo $A S(P<0,05$, teste de Dunn).

O peso relativo dos pulmões, expresso pela razão entre o peso do pulmão/peso do animal está demonstrado na figura 2. A ingestão de álcool provocou aumento do peso relativo dos pulmões, em ambos os períodos avaliados; no entanto, esta diferença não foi significante. 


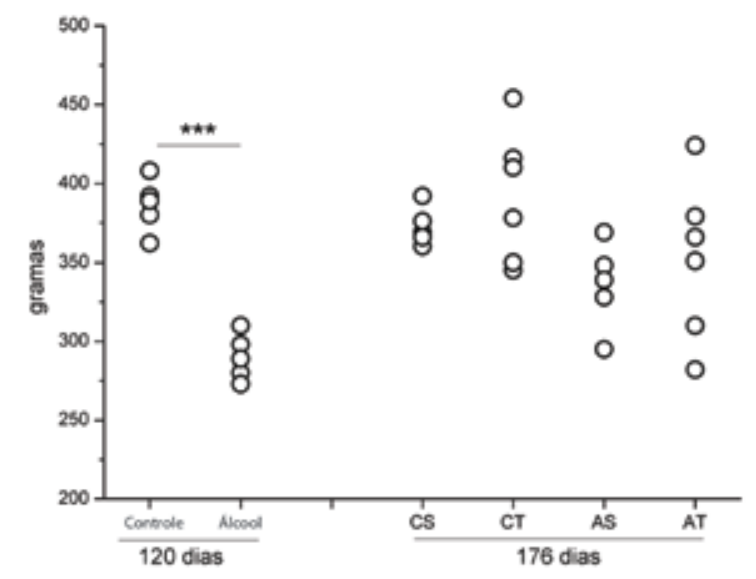

Figura 1. Avaliação do peso dos ratos Wistar controles ou submetidos à dieta alcoólica (álcool) durante 120 dias, animais controles mantidos em sedentarismo (CS) ou treinados (CT) e animais após dieta alcoólica mantidos em sedentarismo (AS) ou treinados (AT) sacrificados aos 176 dias. Animais do grupo álcool apresentaram redução significativa de peso em relação ao grupo controle ( ${ }^{* *} P<0,005$, teste $t$ de Student).

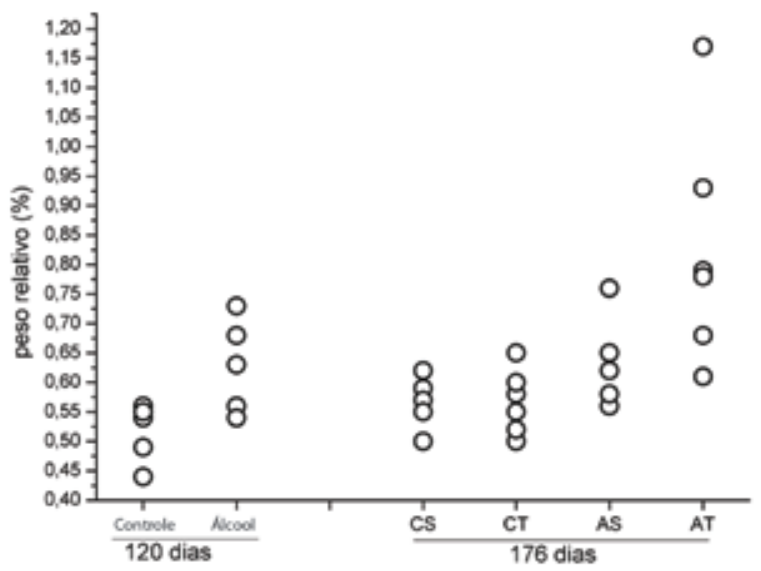

Figura 2. Peso relativo dos pulmões dos ratos Wistar controles ou submetidos à dieta alcoólica (álcool) durante 120 dias, animais controles mantidos em sedentarismo (CS) ou treinados (CT) e animais após dieta alcoólica mantidos em sedentarismo (AS) ou treinados (AT) sacrificados aos 176 dias. Não foi observada diferença entre os animais aos 120 dias $(P>0,05$, teste $t$ de Student) e após 176 dias $(P>0,05$, teste de Kruscal-Wallis).

Os animais do grupo controle CS e CT apresentaram morfologia pulmonar normal (figura 3a, 3c e 3e). Os animais alcoolizados apresentaram lesões pulmonares caracterizadas por inflamação dos septos interalveolares nas regiões periféricas e lobos inferiores dos pulmões (figura 3b). Os infiltrados inflamatórios predominaram na periferia das veias interlobulares. Os septos alveolares apresentaram espessamento devido à vasodilatação capilar e infiltrado difuso de células inflamatórias (macrófagos e neutrófilos).

Os animais AS apresentaram quadro de edema pulmonar semeIhante ao observado nos animais alcoolizados; porém, limitado às regiões dos septos interlobulares (figura $3 \mathrm{~d}$ ). Nas regiões periféricas do órgão, houve redução do espessamento das paredes alveolares e predomínio de macrófagos. Próximo às veias foram observados macrófagos com citoplasma repleto de pigmento férrico (células da hipertensão). Os animas do grupo AT apresentaram áreas mais extensas de edema interalveolar e infiltrado de macrófagos (figura 3f), em relação ao grupo AS.

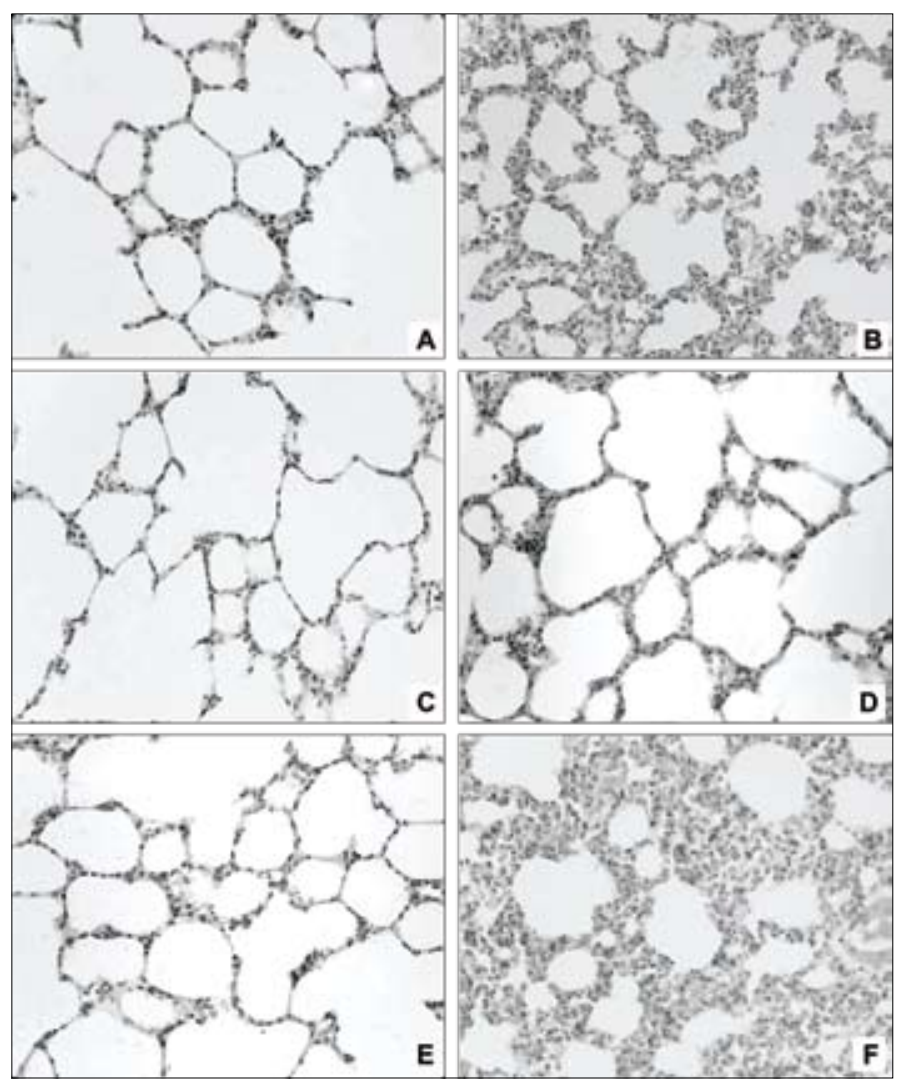

Figura 3. Fotomicrografia de pulmão de ratos Wistar. a) Animais do controle, submetidos à dieta líquida com água potável apresentaram aspecto de normalidade em parênquima pulmonar. b) Animais do grupo alcoolizado, submetidos à dieta líquida com álcool apresentaram vasodilatação nos septos interalveolares, edema pulmonar e infiltrado inflamatório. c) Animais do CS apresentaram aspecto de normalidade. d) Animais do grupo AS ainda apresentaram áreas de edema de espessamento de septos aos 176 dias. e) Animais do grupo CT apresentaram aspecto de normalidade. f) Animais do grupo AT apresentaram extenso infiltrado inflamatório e edema nos septos interalveolares. Coloração HE, 400x de aumento.

A análise da área relativa de edema demonstrou um aumento significativo da área ocupada pelos septos interalveolares nos animais do grupo álcool em relação ao controle, após 120 dias. Os animais AS apresentaram áreas de edema, após 176 dias. No entanto, o exercício físico promoveu o aumento de área ocupada pelos septos alveolares no grupo AT, indicando aumento do edema (figura 4).

Durante o período experimental, foi observado aumento do número de macrófagos pigmentados nos animais que ingeriram álcool (figura 5). O número de macrófagos pigmentados continuou aumentado após 176 dias, em relação aos grupos CS e CT (figura 6).

\section{DISCUSSÃO}

As evidências experimentais demonstram que a ação direta do álcool e os produtos do seu metabolismo sobre os pulmões provocam lesões nos alvéolos pulmonares que culminam com sinais e sintomas de hipertensão pulmonar, aumento da permeabilidade, edema, inflamação e remodelação do interstício pulmonar ${ }^{(7,8,16)}$. Neste estudo, os animais submetidos à ingestão crônica de álcool apresentaram aumento do peso relativo dos pulmões, refletindo os achados do exame microscópico, com aumento da circulação sanguínea nos septos alveolares e a presença de infiltrado inflamatório composto principalmente por neutrófilos e macrófagos.

Após o período de ingestão alcoólica, os animais AS e AT apresentaram aumento do peso corporal, diminuindo a diferença em relação ao grupo CS e CT. Estes resultados sugerem um processo de reparo dos tecidos após a remoção da dieta alcoólica. No entanto, a redução 


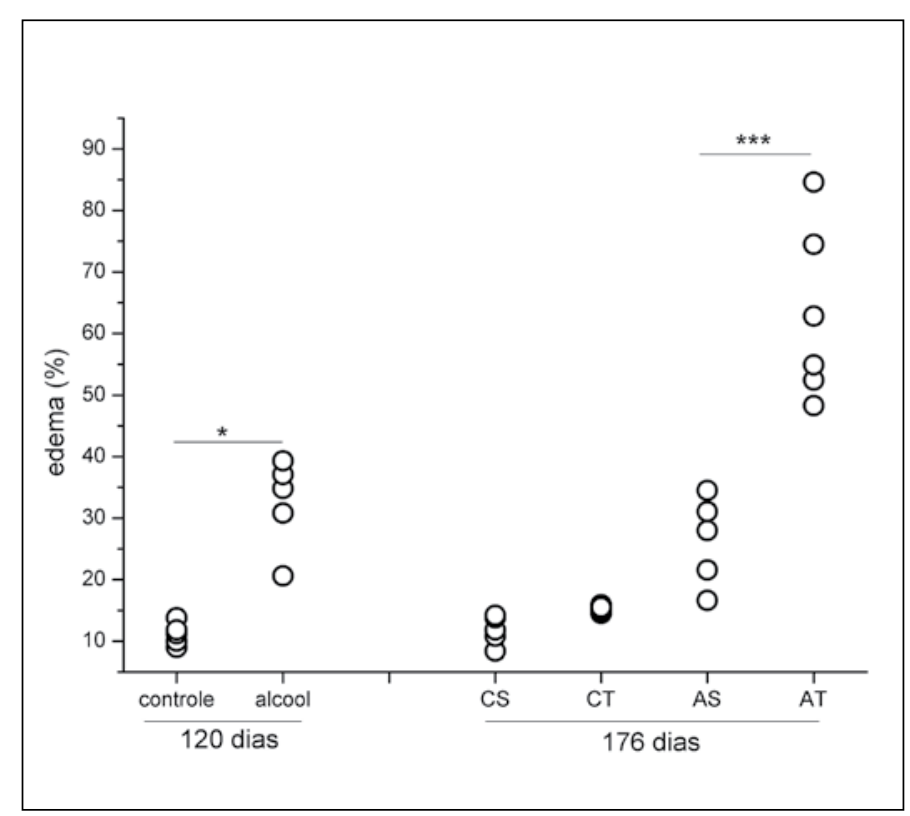

Figura 4. Análise morfométrica da área dos septos interalveolares para avaliação de percentagem de edema dos ratos Wistar controles ou submetidos à dieta alcoólica (álcool) durante 120 dias, animais controles mantidos em sedentarismo (CS) ou treinados (CT) aos 176 dias e animais após dieta alcoólica mantidos em sedentarismo (AS) ou treinados (AT) sacrificados aos 176 dias. Foi observada diferença de porcentagem de ares de edema nos animais do grupo álcool em relação ao grupo controle, aos 120 dias ( ${ }^{*} P<0,05$, teste $t$ de Student). Animais AT apresentaram áreas de edema maiores em relação aos demais grupos ( $P<0,05$, Teste de Dunn). ${ }^{* *}$ Diferença entre o grupo AS e AT ( $P>0,005$, teste de Dunn).

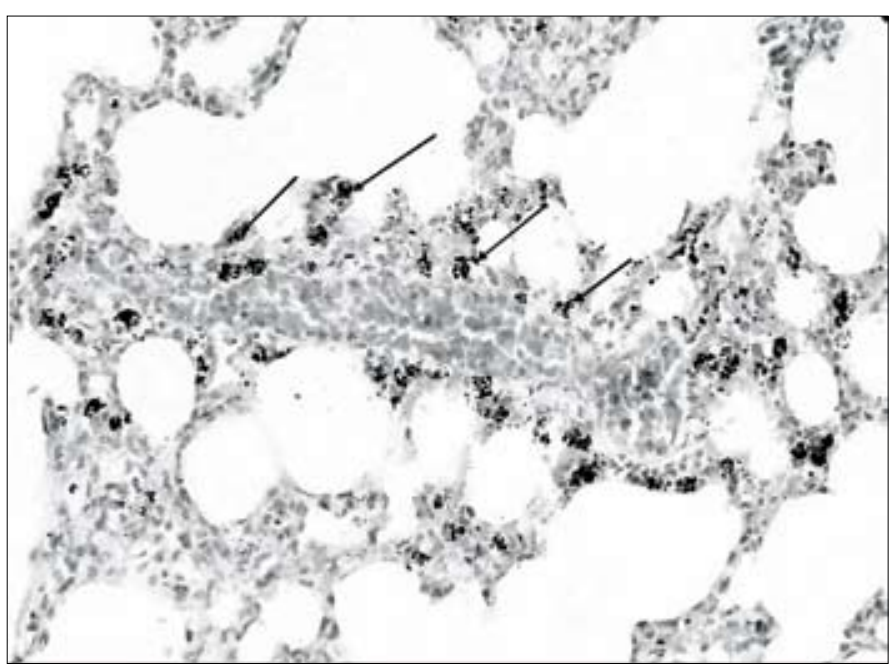

Figura 5. Fotomicrografia de pulmão de rato Wistar, veia interlobular, grupo AT. As setas indicam macrófagos com citoplasma contendo pigmento férrico (células da hipertensão).

da massa relativa dos pulmões continuou aumentada nos animais AT e pode-se observar diferença também no consumo de líquidos, indicando que um estado de desequilíbrio hídrico ainda poderia estar presente nestes animais após 176 dias.

Ao exame microscópico, os animais dos grupos AS e AT ainda apresentavam espessamento das paredes alveolares e vasodilatação dos capilares, aos 176 dias. Outra alteração microscópica evidente nos animais AS e AT foi a presença de grande número de macrófagos contendo pigmento férrico. Os macrófagos contendo pigmento férrico são achados comuns na hipertensão pulmonar, resultado da fagocitose de hemácias extravasadas para o interstício dos septos alveolares e alvéolos pulmonares ${ }^{(17)}$. A presença de maior número destas células nos animais AT sugere que o treinamento físico pode ter contribuído para o agravamento da lesão pulmonar. Além disso, o aumento no peso

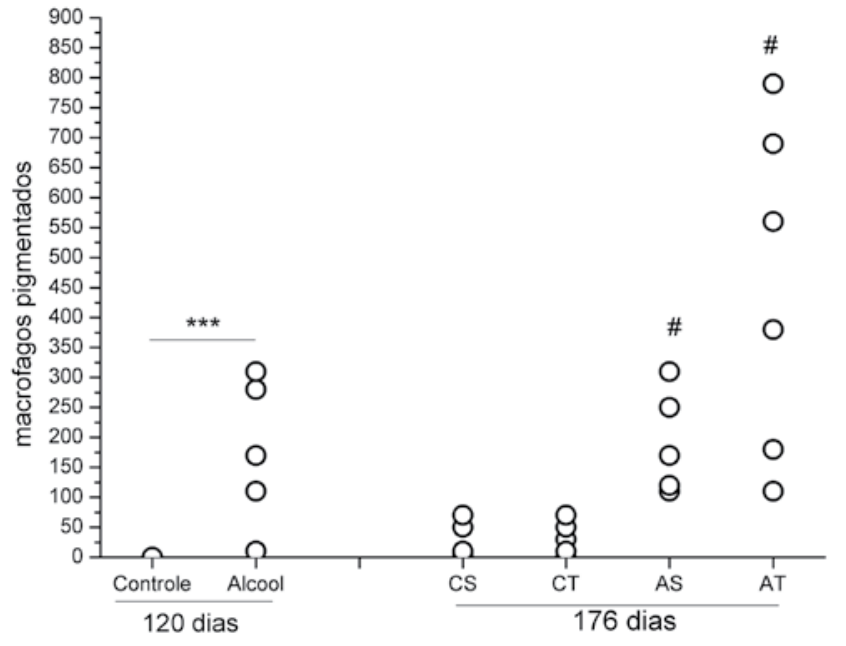

Figura 6. Análise morfométrica do número de macrófagos contendo pigmentos férricos (células da hipertensão pulmonar) em 10 áreas (aumento de 400 vezes) de septos interalveolares de ratos Wistar controle ou submetidos à dieta alcoólica (álcool) durante 120 dias, animais controles mantidos em sedentarismo (CS) ou treinados (CT) aos 176 dias e animais após dieta alcoólica mantidos em sedentarismo (AS) ou treinados (AT) sacrificados aos 176 dias. Foi observado aumento do número de macrófagos hiperpigmentados nos animais do grupo álcool em relação ao grupo controle, aos 120 dias ( ${ }^{*} P<0,05$, teste $t$ de Student). Animais AS e AT apresentaram maior número de células em relação aos grupos CS e CT, respectivamente (\# $P<$ 0,01 , teste de Dunn)

relativo dos pulmões e da área de septos interalveolares e a evidente presença de vasodilatação capilar sugerem que o exercício físico, mesmo em baixa intensidade, induz ao aumento do quadro inflamatório e do edema pulmonar.

A relação entre o abuso de álcool e doença pulmonar é reconhecida como fator de risco para as lesões pulmonares agudas causadas por pneumonia, maior susceptibilidade e maior severidade da tuberculose pulmonar e síndrome do desconforto respiratório agudo ${ }^{(18,19)}$. Em pacientes com história de alcoolismo, há aumento do risco de morte devido às complicações pulmonares ${ }^{(4)}$. Pacientes que sobrevivem à doença pulmonar aguda apresentam piora na qualidade de vida e altos custos para o sistema de saúde; além disso, há redução da capacidade de realizar exercícios físicos até dois anos após o episódio ${ }^{(4)}$. Brown et al. ${ }^{(19)}$ sugerem que o exercício físico aeróbio apresenta diversos benefícios na recuperação de indivíduos alcoolistas. Neste trabalho, optamos pelo treinamento de intensidade baixa devido à presença de alterações graves nos tecidos pulmonares após período de ingestão alcoólica. Além disso, estudos clínicos demonstram que indivíduos que sofrem de hipertensão pulmonar ou sobrevivem à síndrome do desconforto respiratório agudo apresentam pouca resistência ao exercício físico ${ }^{(4)}$. Embora o exercício físico moderado possa contribuir para a homeostasia pulmonar em indivíduos saudáveis, a aplicação imediata de treinamento físico nos animais, mesmo em baixa intensidade, parece agravar as lesões provocadas pelo álcool. Os resultados sugerem que a remoção da ingestão de álcool per se permite que o tecido pulmonar inicie o processo de regeneração e reparo; no entanto, o treinamento físico, mesmo que em baixa intensidade e por curto período de tempo, perpetua a lesão pulmonar quando aplicado imediatamente após o período de alcoolização. A presença de lesão do epitélio dos alvéolos pulmonares e a inflamação aguda provocada pelo álcool podem ter contribuído para o aumento da lesão pulmonar quando a pressão intrapulmonar aumentou em função do esforço físico. 
Considerando que o pulmão inicia um processo de reparo após a remoção do álcool, é necessário investigar o efeito do treinamento físico após a diminuição do quadro inflamatório pulmonar.

\section{CONCLUSÃO}

Concluímos que o exercício físico aeróbio pode agravar as lesões pulmonares provocadas pelo alcoolismo quando iniciado em fases em que ainda há edema e infiltrado inflamatório. Após o período de sedentarismo, os animais alcoolizados apresentam sinais de um processo espontâneo de reparo pulmonar que pode ser inibido pelo esforço físico.

Todos os autores declararam não haver qualquer potencial conflito de interesses referente a este artigo.

\section{REFERÊNCIAS}

1. Burnham EL, Halkar R, Burks M, Moss M. The effects of alcohol abuse on pulmonary alveolar-capillary barrier function in humans. Alcohol Alcohol. 2009;44:8-12.

2. Fiske $C T$, Hamilton CD, Stout JE. Alcohol use and clinical manifestations of tuberculosis. J Infect. 2008;57:385-91.

3. Wind J, Versteegt J, Twisk J, van der Werf TS, Bindels AJ, Spijkstra JJ, et al. Epidemiology of acute lung injury and acute respiratory distress syndrome in The Netherlands: a survey. Respir Med. 2007;101:2091-8

4. Joshi PC, Guidot DM. The alcoholic lung: epidemiology, pathophysiology, and potential therapies. Am J Physiol Lung Cell Mol Physiol. 2007;292:813-23.

5. Guidot DM, Roman J. Chronic ethanol ingestion increases susceptibility to acute lung injury: role of oxidative stress and tissue remodeling. Chest. 2002 Dec;122(6 Suppl):309S-14S.

6. Otis JS, Mitchell PO, Kershaw CD, Joshi PC, Guidot DM. Na, K-ATPase expression is increased in the lungs of alcohol-fed rats. Alcohol Clin Exp Res. 2008;32:699-705.

7. Brown LA, Ritzenthaler JD, Guidot DM, Roman J. Alveolar type II cells from ethanol-fed rats produce a fibronectin-enriched extracellular matrix that promotes monocyte activation. Alcohol. 2007:41:317-24.

8. Polikandriotis JA, Rupnow HL, Brown LA, Hart CM. Chronic ethanol ingestion increases nitric oxide production in the lung. Alcohol. 2007;41:309-16.

9. Gündüz F, Sentürk UK, Kuru O, Aktekin B, Aktekin MR. The effect of one year's swimming exercise on oxidant stress and antioxidant capacity in aged rats. Physiol Res. 2004;53:171-6.
10. Ravi Kiran T, Subramanyam MV, Asha Devi S. Swim exercise training and adaptations in the antioxidant defense system of myocardium of old rats: relationship to swim intensity and duration. Comp Biochem Physiol B Biochem Mol Biol. 2004;137:187-96.

11. Husain K, Vazquez Ortiz M, Lalla J. Physical training ameliorates chronic alcohol-induced hypertension and aortic reactivity in rats. Alcohol Alcohol. 2006; 41:247-53.

12. Vila L, Ferrando A, Voces J, Cabral de Oliveira C, Prieto JG, Alvarez Al. Effect of chronic ethanol ingestion and exercise training on skeletal muscle in rat. Drug Alcohol Depend. 2001;64:27-33.

13. Mussi RK, Camargo EA, Ferreira T, De Moraes C, Delbin MA, Toro IF, et al. Exercise training reduces pulmonary ischaemia-reperfusion-induced inflammatory responses. Eur Respir J. 2008;31:645-9.

14. Mallikarjuna K, Nishanth K, Hou CW, Kuo CH, Sathyavelu Reddy K. Effect of exercise training on ethanolinduced oxidative damage in aged rats. Alcohol. 2009;43:59-64.

15. Pereira KF, Conegero Cl. Interfase músculo-tendínea de ratos induzidos a ingestão alcoólica. Acta scientiarum. Biological Sciences. 2004;26:361-4.

16. Fernandez AL, Koval M, Fan X, Guidot DM. Chronic alcohol ingestion alters claudin expression in the alveolar epithelium of rats. Alcohol. 2007;41:371-9.

17. Brasileiro Filho, G. Bogliolo. Patologia. Rio de Janeiro: Guanabara Koogan, 2006.

18. Fiske $C T$, Hamilton CD, Stout JE. Alcohol use and clinical manifestations of tuberculosis. J Infect 2008:57:385-91.

19. Brown RA, Abrantes AM, Read JP, Marcus BH, Jakicic J, Strong DR, et al. Aerobic exercise for alcohol recovery: rationale, program description, and preliminary findings. Behav Modif. 2009;33:220-49. 